\title{
Intertextuality Theory and Translation
}

\author{
Yi Long \\ University of Shanghai for Science and Technology, Shanghai, China \\ Gaofeng Yu \\ University of Shanghai for Science and Technology, Shanghai, China
}

\begin{abstract}
Intertextuality theory is one of the most complicated literary theories in contemporary literary criticism; it has inherent connections with translation. According to intertextuality theory, translation is a type of transforming activity intertextualized with language, text, culture and thinking, etc. Any translated text is a tissue in an immense network of complex, where the significance of each text unfolds through referring to each other. In some degree, intertextuality theory breaks the traditional idea of translation, and has great enlightenment on translation in many aspects.
\end{abstract}

Index Terms - intertextuality, text, translation

\section{INTRODUCTION}

Since the beginning of the 21 st century, translation studies have been further strengthened in both depth and breadth. However, with the emergence of various theoretical schools of humanities and social sciences, some of the cornerstones of translation theories that were previously admired by the translation community may collapse and be overthrown. Instead, it is a state of multi-symbiosis in translation theory guided by dialectical, dynamic and developing philosophical views, which can be used as a reference for other disciplines (Qin, 2002). Intertextuality is a term often used by postmodern masters and deconstructors. Intertextuality, as a text theory produced in structuralism and post-structuralism, involves the meaning generation, reading and interpretation of texts. There are a series of important problems in contemporary western literature and art, such as the relationship between text and cultural practice (Zhu, 2004). The purpose of introducing intertextuality into the study of translation is to help translation theory and practice get out of the closed shell and step into a broader and more open space.

\section{THE ORIGIN OF THE INTERTEXTUALITY THEORY}

"Intertextuality" is an important text theory formed in the trend of thought of western structuralism and post-structuralism. It usually refers to the intertextual relationship between two or more texts. The theory was first proposed by Julia Kristeva, a feminist critic who is a famous French semiotician of Bulgarian origin. While criticizing the unreasonable aspects of structuralism, she developed her own theories inspired by Bakhtin's dialogues and polyphony theories. Intertextuality is a basic feature of discourse. It is, to be precise, the heterogeneous characteristic that various corpora intersect each other in the process of discourse generation, a text that influences and correlates with other texts (Hu, 2006). Any text is an insert of the quotation, and any text is an absorption and adaptation of another (Kristeva, 1986). The other text mentioned by Kristeva is the mutual text in the common sense. It can refer to the social and historical text at the synchronic level, namely the text space of horizontal discourse mentioned above. It can also refer to the works of predecessors or descendants at the diachronic level, namely the vertical relationship dimension of the text. The absorption and adaptation of the text can be realized in the text by means of parody citation and collage (Zhang, 2009). Intertextuality indicates that all texts exist in the relationship with other texts. Texts in different space-time intersect to form a large system, and any single text exists as a part of the system. It can be seen that what Kristeva emphasizes is the internal process of text recombination or transformation, in which the corpus from other texts is combined into a new meaningful text according to its function (Xin, 2000).

\section{ClasSification OF INTERTEXTUALITY}

So far, many scholars have made many attempts on the classification of intertextuality and proposed different classification methods. Kristeva divides intertextuality into horizontal intertextuality and vertical intertextuality. The so-called horizontal intertextuality refers to the conversational intertextuality between a paragraph of discourse and a series of other discourses, while the vertical intertextuality refers to those contexts that constitute a discourse directly or indirectly, that is, those discourses that are related to it in various ways from the perspective of history or the contemporary era. Hatin and Mason divide intertextuality into positive intertextuality and negative intertextuality. Positive intertextuality refers to the knowledge and value beyond the text, while negative intertextuality is just to make the text coherent. Jenny divides intertextuality into strong intertextuality and weak intertextuality. Strong intertextuality refers to the fact that a certain text contains discourses related to other discourses, and such a degree is usually obvious, 
such as quotation plagiarism, etc. Weak intertextuality refers to some content expressions in a text that semantically can arouse associations to other texts, such as similar ideas and themes. Genette refines and clarifies the intertextuality of the text. He believes that intertextuality should be called as "transtextuality". He divides transtextuality into five main types: Intertextuality, quasi-textuality, meta-textuality, hypertextuality and universalism, emphasizing the hierarchical relationship between text and its intertextuality. Michael Riffaterre, however, constructs a triangle among text, intertext and ideograph, believing that all texts are a matrix and called the first text, while intertextuality belongs to the second text and ideography to the third or second intertext (Cheng, 1996). Therefore, when readers interpret the meaning of a text, they must gather more than one text and consider it together, and incorporate it into the interwoven network of texts for interpretation. This interpretation put forward multidimensional problems of intertextual interpretation, and at the same time demonstrates the openness and infinity of intertextual relations (Zhu, 2004). It can be seen that they emphasize the interaction and influence between text forms and text contents no matter how they classify.

\section{THE ENLIGHTENMENT OF INTERTEXTUALITY THEORY TO TRANSLATION}

Intertextuality is characterized by the relevance and comprehensiveness of language and text. In the field of language activities, texts interweave with other texts while self-referential. Intertextuality adds a new dimension to translation studies (Chen, 2009). The implications of intertextuality on translation are reflected in the following two aspects.

\section{A. Intertextuality Breaks the Traditional View of Meaning in Translation}

In a sense, the history of translation is a history of the transformation of meaning. Although scholars have different views, as far as the criterion of translation is concerned, the quality of translation mostly depends on the degree to which the transformation of meaning is faithful to the meaning of the original text (Zhu \& Lin, 2002). Eugene a. Nida, A famous American translation theorist, believed that translation refers to the reproduction of the information of the source language in the closest and most natural equivalent from semantics to style in the target language (Tan, 2000). Hirsch, an American writer and professor at the University of Virginia, believed that the key to the development of modern western philosophy and humanities lies in the pursuit of meaning and the grasp of the true level of meaning (Wang, 2001). Gentzler, director of the Translation center of the University of Massachusetts Amherst in the United States, said in his book Contemporary Translation Theories that the traditional view of meaning of structuralism holds that meaning is fixed and unchangeable. Different readers can interpret the same text to obtain a unified meaning (Gentzler, 1993).

But according to the theory of intertextuality, the identity of meaning or the certainty of meaning seems to be weak. Translation has the characteristics of intertextuality both in appearance and in essence. It can be said that translation itself is an intertextuality activity. Derrida, a French thinker and representative of deconstructive philosophy, believed that translation is the conversion from one language to another and the replacement of one text to another. Translation is a process of language conversion in a text network that integrates multiple meanings. Kristiva also strongly opposed the idea of meaning certainty. She divided the text into phenomenological text and genetic text, and believed that genetic text stipulated the logical operation unique to the composition of the subject of expression, and it was the place where phenomenological text was structured and meaning was generated (Huang, 1999). In his book exploration of contemporary western translation theories, Professor Liao pointed out that in terms of space, symbols are always limited by other symbols, so symbols are not the same, and their meanings are also dependent on other symbols, so their meanings are uncertain and can only be distinguished by context. In terms of time, the symbol is always the place of holding up signified, so there is no constant meaning (Liao, 2000). As a result, literature, including literary meaning, becomes an unstable process of countless signifier imprints and infinite changes. It can be seen that the mutual reference between texts, the absorption and adaptation of one text to another form a radiating body of meaning. The generation of meaning is constantly interwoven, radiated, diffused and proliferated in the text network, so the meaning is uncertain and not invariable. Since translation is a process of language transformation in a text network that integrates multiple meanings, it can be said that translation is a process of the dialogue and communication between the original author, translator and readers across time and space, as well as an interactive process of selection, absorption, creation and variation. In this process, there is often some kind of infinite supplement, replacement, broadcast and proliferation of meaning. Even with different degrees of misinterpretation, it is still a derrida-style "gain" or "supplement" intertextuality conversion activity.

From a deeper perspective, intertextuality is not only reflected in the level of language and text, but also deeply hidden in the thinking and psychological activities of the original author, translator and translation reader as well as the critics. Therefore, the translator, as an intermediary between the author of the original text and the reader of the target text, needs to read a large number of previous texts, which are directly or indirectly related to the author's intention, the subject of the text and the connotation of the text. In addition, the reception psychology of the readers in the cultural system of the target language should be fully considered, and the intertextual reference in different cultures should be compared and contrasted. When translate, the translator can guide the reader to understand the intertextual association between the source language culture and the target language culture, satisfy the reader's desire and expectation for the cultural knowledge of the target language, and seek the intertextual association similar to the source language culture in the target language culture, fully reflecting the readability and acceptability of the translation (Chen, 2009). 
In general, the process of translation is not only the conversion between languages and between texts and meanings, but also the mutual supplement of many original texts and many translated texts in a broader space and time, so as to create richer meanings than mere reproductions or duplications.

\section{B. Intertextuality Theory Puts forward Higher Requirements for Translators.}

As we know, the intertextuality theory emphasizes the nondeterminacy of text structure, and no text can exist without other texts. Text meaning depends on the interaction between the text and other texts. Specifically, the intertextuality theory includes the following three aspects: the completion of the text, the interpretation of the text and the rewriting of the text. And any of these aspects need to be accomplished using intertextuality knowledge. Translation is the transformation of text and meaning between languages. The translation itself is intertextual, and the original text and the translation are intertextual. Therefore, if we see the original text as a previous text, the translation should be the generated text of the previous text. In the conversion process from pre-text to generated text, that is, in the translation process, the translator plays three roles at the same time: the reader of the pre-text, the elucidator and the author of the generated text, and performs three tasks of completing, interpreting and rewriting the text in intertextuality (Zhu, 2004). To a large extent, the exertion of the translator's subjectivity determines whether this process can be successfully completed. Therefore, the translator should perform his/her duties, fully understand the source text, and play the role of the medium of the source text and the target text.

1. Translator as a reader

As a reader, the translator should first carefully read the original text, that is, he or she should read the original text as a reader. The Italian symbologist Umberto Eco said that no text could be read without any other text. That is to say, when reading the original text, the reader should make use of the intertextuality knowledge associated with the original text to fully understand the meaning of the original text. Furthermore, a text has meaning only when it is read, and the production of this meaning often depends to a great extent on the fusion of the field of view with the work (the text), as H. R. Jauss called it. Therefore, it requires translators as readers to combine their own social background and cultural background, give full play to their subjective initiative, carefully interpret the original text, and complete the text. However, according to the intertextuality theory, no text can be completely completed, because each new reader will bring his or her unique "competence model" into the reading process and fill the gaps in the text with different methods due to the different social and cultural backgrounds of his own era (Sun, 2008). To be precise, any reader only completes the text relatively, not absolutely, but each relative completion is a step toward absolute completion

2. Translator as elucidator

The translator's second role is to elucidate the intertextuality theory, which requires the translator to grasp the text at a higher level and elucidate the original text carefully. Therefore, as elucidators, translators must first be familiar with the relevant literary themes and the historical and social background implied in the text. Secondly, translators must be familiar with all kinds of skills or strategies needed to express the unfamiliar content, and at the same time fully explore and display their literary connotation, so that they can perform their duties as elucidators from the content to the form to the overall style. As Eliot said, the young poets follow the example, and the mature poets try to change the source text (Scholes, 1988). Such changes refer to the mutual refraction in the intertextual theory. Only when the translator gives full play to his/her subjectivity, can he/she make a reasonable elucidation of various intertexts (Zhu, 2004).

3. Translator as an author

The translator's third role is the author. That is to say, after the translator completes the role of reader and elucidator, he or she needs to express the pre-text in another language, performing conscious or unconscious rewriting of the pre-text and reflecting a direct or indirect intertextual relationship. According to the process of translation, the translator has to shuttle back and forth in the interwoven network of texts to get his/her own understanding and the product of understanding, namely meaning, and then turn the product of understanding into the final product of translation, namely translation. This is a process of creation and re-creation, which needs the full play of the translator's subjectivity. Italian aesthetician and literary critic Benedetto Croce thinks that literary translation is the recreation of art, the translation is the regeneration of the original text, and the translator is the giver of the regeneration of life (Tan, 2000). British translator Andre Lefevere believes that whether translators can reproduce the original text depends on their skills as artists (Lefevere, 1995). Therefore, to what extent a translation can be revived depends entirely on the translator's subjectivity and creativity, in which intertextuality plays an important role (Zhu, 2004). Of course, the degree of translator's creativity also needs to be considered, the key is to be faithful to the original text and reflect the translator's style. Just as Mr. Qian quoted Confucius to say that one should follow one's heart and do what one wants without exceeding the rules, the rules here are about degree.

\section{THE APPLICATION OF INTERTEXTUALITY THEORY IN TRANSLATION}

To sum up, we know that no text (literary or non-literary) can be interpreted in isolation, and there are traces of intertextuality in any text (Wang \& Liu, 2008). Therefore, the interpretation of any text requires the help of a large amount of mutual knowledge related to the text in order to get the correct interpretation. Kristiva once said in her book "novel text" that any text hides the accumulation of cultural traditions of a culture and is a book in the book. Translation is a kind of semantic transformation between two languages of different cultures. Therefore, in the process of translation, 
translators should consider not only the faithful transmission of the semantics of the original text, but also the reception ability of the target readers and the effect of the post-language behavior of the target text. Readers of the two cultures have different backgrounds, so their views and experiences are different. Because the source reader has the background knowledge or the cultural pragmatic presupposition to understand the source culture, they can correctly understand the intertextual text in the source culture. But if the original text is translated into the target language, for readers who lack the background knowledge of the source culture or cultural pragmatic presupposition, they will be confused or misunderstood. Therefore, in the actual translation, the translator should add necessary preset information according to different situations to meet the understanding requirements of the target readers. Only in this way can the translation be completed in the mutual reference of many texts

Example sentence (1): “姑娘别误听了小孩子的话！柳嫂子有八个脑袋，也不取得罪姑娘。”

Translation: "Don't believe what those children say, Miss. Even if Mrs. Liu had nine lives, she'd never dare offend you."

The English proverb "A cat has nine lives" is cleverly used in the translation. The “八个脑袋（eight heads）” in the original text is translated into "nine lives". Although the figurative images and expressions are different, they have the same semantic meaning and all expresses strong validity. If translated into "eight heads", it may cause difficulties in the understanding of the target readers. The translator uses the intertextual approach to carry out functional equivalence translation, which is in line with the aesthetic taste of the target readers. Therefore, in the translation practice, the translator can make full use of the advantages of the target language and apply the intertextuality theory, so that the target language can produce the image effect consistent with the target language culture in the new context.

Example sentence (2): Men sent flowers, love notes, offers of fortune. And still her dreams ran riot. The one hundred and fifty! The one hundred and fifty! What a door of an Aladdin's cave it seemed to be. (Theodore Dreiser: Sister Carrie)

译文: 男人送花, 送情书, 送时运给她。可她梦幻无边。这一百五十块钱！这一百五十块钱！真像藏着神灯 的山洞为阿拉丁打开了门.

The readers of the original text are quite familiar with the cultural background of the allusion of Aladdin's cave, so it will not cause any difficulty in understanding. However, for most Chinese readers, they may not necessarily understand the meaning of the allusion, and they lack the intertextuality knowledge related to it. Taking full account of the lack of intertextuality among the readers of the target text, the translator translated it as “真像藏着神灯的山洞为阿拉丁打开 了门 (a cave with a magic lamp that opens the door for Aladdin)." In this way, the cultural losses caused by literal translation are compensated, and the original author's information intention and communicative intention are in line with the Chinese readers' aesthetic expectations, achieving excellent communicative effects

Example sentence (3): Those were the words that were to make the world blossom for me, "like Aaron's rod, with flowers" (Helen Asams Keller, The Story of My Life).

Translation: 后来就是这些词把一个美好的世界展现在我的面前, 就像《圣经》上说的“亚伦的杖开了花”一样。

Aaron's rod refers to any rod used by Aaron, the brother of Moses. According to Old Testament book of Numbers 17:1-11, Aaron's rod had the same magical power as Moses' rod, which was given to him during the plagues of Egypt before he came out of Egypt. It was placed before the ark of the covenant by Moses, and it germinated and blossomed and bore fruit. This rod of Aaron became a special relic of Judaism. After understanding the intertextual knowledge of the allusions, the translator adds "said in the bible" before the quotation marks, which not only points out the source of the allusions, but also provides the relevant background knowledge, making it easier for the translation readers to obtain the information intention of the original author, and easier for the translation readers to understand.

\section{CONCLUSIONS}

From the above discussion, we can clearly see that the theory of intertextuality has certain enlightening effect on translation in many aspects, and it is intrinsically related to translation. The intertextuality of texts enables translators to find relevant evidences and references in translation practice, but the intertextuality of texts also puts forward higher requirements for translators in terms of cultural quality. Therefore, in the practice of translation, translators should try to broaden their minds, deepen their understanding of the essence of translation, make themselves become a miscellaneous person with rich cross-cultural knowledge, and accumulate as much information as possible about the social history and culture of their own country and foreign countries. Only in this way can the translator correctly grasp the intertextuality phenomenon in the text and make full use of the relevant intertextuality knowledge in the text in order to accurately interpret the cultural connotation and communicative information in the original text, so that the translator can make the translation conform to the social trends, cultural habits and linguistic habits of the target language, and to make his or her contribution to the promotion of cultural exchanges among the countries of the world.

\section{REFERENCES}

[1] Chen, C. (2009). Application of intertextuality theory in translation practice. Journal of huanggang normal university, 4, $135-138$.

[2] Cheng, X. (1996). Introduction to intertextuality theory. Foreign literature, 1, 72-78. 
[3] Genette, G. (1977). Palimpsests: Literature in the Second Degree. Lincoln and London: University of Nebrask Press.

[4] Gentzler, E. (1993). Contemporary translation theories. London: Routledge.

[5] $\mathrm{Hu}, \mathrm{H}$. (2006). Inheritance and development of literature and culture from the perspective of intertextuality. Academia, 5, 205-209.

[6] Huang, N. (1999). Intertextuality theory in contemporary western literary thory. Foreign literature research, 1, 15-21.

[7] Kristeva, J. (1986). The Kristeva Reader. Oxford: Basil Blackwell.

[8] Lefevere, A. (1995). Introduction: Comparative Literature and Translation. Comparative Literature, 47(1), 1-10.

[9] Liao, Q. (2000). Exploration of contemporary western translation theory. Jiangsu: Yilin press.

[10] Qin, W. (2002). Between the lines of the translated text. Foreign languages, 2, 53-58.

[11] Sun, S. (2008). Intertextuality theory and translator's identity. Journal of Hebei university of science and technology, 4, 180-182.

[12] Scholes, R. E., Comley, N. R., \& Ulmer, G. L. (1988). Text book. An introduction to literary language. New York: St. Martin's Press.

[13] Tan, Z. (2000). A brief history of western translation. Beijing: commercial press.

[14] Wang, H. \& Liu, Y. (2008). Translation of contract regulations from the perspective of intertextuality. China translation, 6, 64-68.

[15] Wang, Y. (2001). Phenomenology and hermeneutics. Shandong: shandong education press.

[16] Xin, B. (2000). Pragmatic analysis of intertextuality. Foreign language studies, 3, 14-16.

[17] Zhang, C. (2009). Advertising discourse analysis from the perspective of intertextuality. Journal of changchun university of science and technology, 4, 130-131.

[18] Zhu, Z. (2004). Intertextuality and translation studies. Journal of PLA foreign languages university, 4, 71-74.

[19] Zhu, Z. \& Lin, P. (2002). Poetry: translation and adaptation. Foreign language research, 4, 71-74.

Yi Long was born in 1995. She is currently a postgraduate student in the College of Foreign Languages, University of Shanghai for Science and Technology, Shanghai, China. Her major is Translation and Interpretation.

Gaofeng Yu graduated from Nankai University in 1988. He is currently an Associate Professor at University of Shanghai for Science and Technology. His research interests mainly are cognitive linguistics and translation theory and practice. 